Volume 8. No. 10, October 2020

International Journal of Emerging Trends in Engineering Research

Available Online at http://www.warse.org/IJETER/static/pdf/file/ijeter1118102020.pdf

https://doi.org/10.30534/ijeter/2020/1118102020

\title{
The Proposal to Choosing a Rational Number of Elements in the Multiradar System Structure
}

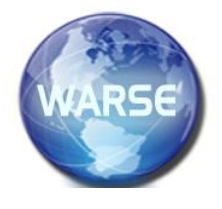

\author{
Hennadii Khudov ${ }^{1}$, Vitaliy Lishchenko ${ }^{2}$, Oleksandr Pukhovyi ${ }^{3}$, \\ Serhii Popov ${ }^{4}$, Ruslan Kolos ${ }^{5}$, Nazar Shamrai ${ }^{6}$
}

${ }^{1}$ Department of Radar Troops Tactic, Ivan Kozhedub Kharkiv National Air Force University, Kharkiv, Ukraine, 2345kh_hg@ukr.net

${ }^{2}$ Department of Radar Troops Tactic, Ivan Kozhedub Kharkiv National Air Force University, Kharkiv, Ukraine, lvnpo4ta@gmail.com

${ }^{3}$ The Department of Radio-Technical and Special Troops, Ivan Cherniakhovskyi National Defence University, Kyiv, Ukraine, puhovij@ukr.net

${ }^{4}$ The Department of Radio-Technical and Special Troops, Ivan Cherniakhovskyi National Defence University, Kyiv, Ukraine, s.e.popov.71@ukr.net

${ }^{5}$ Department of Tactics of Combat (Operational) Support Unit, Hetman Petro Sahaidachnyi National Army Academy, Lviv, Ukraine, kolosrus@i.ua

${ }^{6}$ Department of Tactic and Military Disciplines, Ivan Kozhedub Kharkiv National Air Force University, Kharkiv, Ukraine, samrajnazar46@gmail.com

\begin{abstract}
The subject of research in the paper is the problem of choosing a rational number of elements in the structure of a multiradar system of the same type of two-coordinate surveillance radars with mechanical rotation. The purpose of the paper is determination a rational number of multiradar system elements, which will provide an optimal improvement in the quality of detecting air objects according to the cost-effectiveness criterion. To improve the quality of detection of small-sized objects, surveillance radar stations are combined into a spatially separated multiradar system. An assessment of the characteristics of detecting air objects in a multiradar system with a matched signal reception is carried out. The calculations were carried out for systems that consist of a different number of elements. The calculations show that the addition of second radar, regardless of the degree of signal coherence, showed the greatest efficiency in terms of signal-to-noise ratio, the rational number of radars in a multiradar system is no more than four. In a multiradar system of four radars, the threshold signal-to-noise gain can be up to eighteen decibels for a system with coherent signals and up to eleven decibels for a system with incoherent signals. More than four radars are impractical.
\end{abstract}

Key words :rational Number, element, radar, multiradar system, structure, signal-to-noise ratio

\section{INTRODUCTION}

The analysis of the experience of airspace control in the last decade, especially in modern local wars, including in conditions of hybrid hostilities, such as in Syria and Nagorno-Karabakh, showed that reliable radar detection of air objects is significantly complicated by the appearance of small-sized (with low radar signature) [1]-[4].

It is known that small unmanned aerial vehicles (UAVs) in most cases were not detected by the available standard radars [5]-[13], which previously successfully coped with the tasks of air traffic control and aircraft detection without identification signals.

Manufacturers of radar equipment around the world are implementing the latest advances in science and technology: serial-parallel electronic scanning of space in the vertical plane and two-dimensional electronic scanning of the antenna directional pattern, adaptive phased antenna arrays, digital synthesis of probing signals with various parameters, digital pattern formation [14]-[32].

Currently, the radar equipment is being updated, the newest and modernized models of radar stations appear, including those that use wideband phased signals and digital phased antenna arrays, but this process is gradual and expensive. Therefore, in general, the existing equipment does not provide a complete solution to the tasks set, especially in terms of detecting an inconspicuous airborne object.

At the same time, airspace monitoring provides a large number of two-dimensional surveillance radars of the P-18 type and its numerous modernized modifications. These radars are not capable of ensuring the detection of a modern, inconspicuous airborne object with specified quality indicators [26], [28], [31], [33]-[34].

Thus, at present, when solving the problem of detecting an inconspicuous airborne object, the discrepancy 
between the development trends of airborne objects and the capabilities of existing radars for detecting inconspicuous and small-sized airborne objects with the required efficiency has become aggravated.

To eliminate this discrepancy and improve the efficiency of detecting an unobtrusive airborne object, it is proposed to combine the existing two-coordinate surveillance radars into a coherent multiradar system (MRS) with compatible signal processing [3], [13], [16], [19], [26]-[28], [31], [33].

It's clear that the quality of detection in such a multiradar system will increase with the addition of each additional radar, but how many should be based on the cost-quality criterion is important to know. Therefore, the task of determining the rational number of elements is an urgent task. Wherein solving this problem of determining the rational number of elements of a multiradar system will provide an opportunity to formulate practical recommendations to improve the efficiency of radar equipment.

\subsection{Problem analysis}

Today, the proliferation of consumer UAVs increasingly complicates the work of air traffic control authorities in the field of ensuring the safety of airport airspace. As part of a program to prevent drone access to airports, governments around the world are equipping some airports with air defence systems that scan the space to identify drones and use directional radio waves to neutralize them [35].

The tasks of searching and detecting an inconspicuous airborne object are solved by observation with the use of radio, infrared, optical, acoustic and combined reconnaissance means (Figure 1) [36]-[48]. This is all the more important given that unmanned aerial vehicles are not a toy, but a real security threat. History has already documented cases where the operation of large airports was paralyzed, which led to huge negative economic consequences and revealed problems in the security sector. This was a consequence of the unauthorized launch of multicopters in the area of the runways.

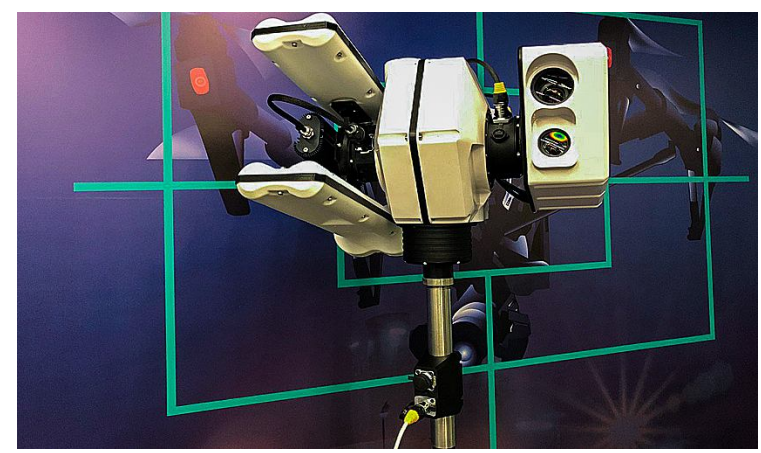

Figure 1. Existing methods for detecting inconspicuous air objects
UAVs are not only difficult to control but even detection. In the future, the risks associated with launches of household multicopters and the increase in unmanned aerial vehicles, for example, in the field of logistics will only increase. A fatal plane crash or a drone attack is just a matter of time. Unmanned aerial vehicles can also threaten the unauthorized crossing of the state border and being near especially important and dangerous objects, such as nuclear power plants, not noticed by the relevant airspace control services and special services.

Each of the methods that are currently being used has its own advantages and disadvantages. The using of the radar method has undeniable advantages over other methods [7]-[9], [15], [17]. In addition to the well-known radar methods, non-standard ones have recently been developed and widely used: the use of external sources of radio signals, the use of the radar effect, the use of combined passive-active radar systems, and others.

All modern methods are based on a general trend in the development of technology - the integration of individual devices (instruments) into systems [3], [13], [16], [19], [26]-[28]. There is already a line of different types of multiradar systems based on this trend. The individual positions of the elements of such systems are spatially separated from each other, and the processing of radar information is carried out centrally in one processing point, which can be combined with one of the positions or located separately. At this stage, it is advisable to carry out joint processing of radar information, the effectiveness of which depends on the degree of consistency provided in the system.

The purpose of the paper is determination a rational number of multiradar system elements, which will provide an optimal improvement in the quality of detecting air objects according to the cost-effectiveness criterion.

\section{MAin Material}

The creation of a small-base multiradar system makes it possible to solve the problem of increasing the energy potential of the radar, increasing the gain of antenna systems using available resources due to the appearance of systemic effects. Combining autonomous radars into a multiradar system provides the emergence of new qualities - systemic effects [3], [13], [16], [19], [26]-[28], [31], [33]. In this case, it becomes possible to implement different degrees of coherence of spatially separated positions in the system and combined reception of echo signals.

The article describes how to choose a rational number of elements in a system in which the existing two-coordinate surveillance radars are combined into a synchronous multiradar system (Figure 2). 
The number of radars to create an effective system will be determined by the specific gravity of the gain that each radar adds when calculating the signal-to-noise ratio. Each additional radar will add additional energy to the system and increase the synthetic aperture of the antenna. However, it is necessary to calculate the rational number of system elements at which the maximum effect will be ensured by the quality-cost criterion.

An important point when creating a multiradar system is the possibility of creating a synchronous coherent multiradar system in the presence of spatially separated radars. The creation of coherence necessitates the fulfilment of the following conditions: frequency synchronization, phase synchronization, time synchronization, review of the same area of space simultaneously by all radars. Figure 3 shows an example of building a multiradar system.

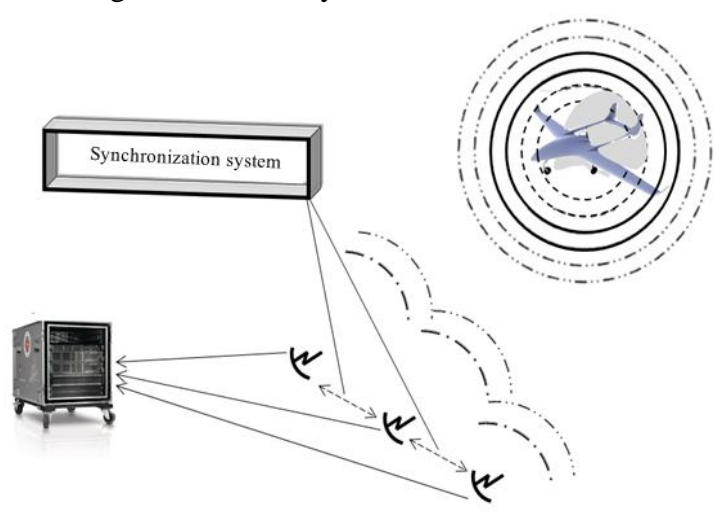

Figure 2. Forming an agreed inspection area small-base multiradar system of the surveillance same type radar

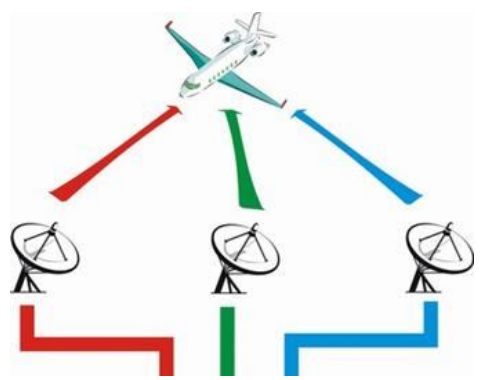

Figure 3. Multiradar system on the example of a synchronous small-base system with three radars

Each element of the system, and we have a radar, emits its own transmission signal, which does not correlate with the transmission signal of other radars. All radar signals are transmitted synchronously. Non-correlation (orthogonality) can be ensured: frequency diversity (frequency); signal coding (code). All system radars receive reflected signals:

- its emitted signal is reflected from an airborne object; - reflected from an airborne object, transmitting a signal from neighbouring radars.
Depending on the design of the synchronization system of the multiradar system, the signals emitted by the radar can be mutually coherent or incoherent. Therefore, in a multiradar system, methods for processing mutually coherent or mutually incoherent signals can be implemented. We will consider the coherent case; for our calculations, it will not fundamentally differ from the incoherent case.

Method of processing coherent signals in a multiradar system. Consider a multiradar system in which each radar emits mutually orthogonal signals. These signals are reflected from an air object of complex shape. If the size of the air object is much larger than the wavelength, the signals received by each radar fluctuate. As a rule, amplitude fluctuations are described by Rayleigh law, and phase fluctuations are evenly distributed in the interval $(-\pi, \pi)$. The nature of the fluctuations of the signals received by different radars depends on the degree of their spatial correlation, which is determined by the size of the effective base (distance) between the radar (expression (1)):

$$
\frac{\mathrm{L}_{\mathrm{ef}}}{\mathrm{R}}>(0.8 \ldots 1) \frac{\lambda}{\mathrm{l}_{\mathrm{AO}}} .
$$

where $\mathrm{L}_{\mathrm{ef}}=\mathrm{L} \sin (\theta)$ - effective base between spatially spaced radars $(\theta-$ the angle that determines the direction of the air object); $\mathrm{R}$ - range to the air object from the middle of the effective base; $\lambda$ - radar wavelength; $1_{\mathrm{AO}}-$ transverse size of the air object (parallel to the effective base).

At full spatial correlation, the complex amplitudes and initial phases of the signals at the inputs of different positions are strongly connected and fluctuate amicably. Therefore, such signals are spatially coherent. At small bases between receiving positions rigid communication between complex amplitudes of echo signals in various positions (full time correlation) is possible.

At the input of the radar receiver in each position receives signals emitted by all radar. If all radars emit the same signals in such a way that their in-phase summation on the air object is ensured, then at the input of the receiving positions there will be only one echo signal. The effective value of the amplitude of the echo signal in this case will be equal to the sum of the effective values of the echo signals formed by all transmitting positions [22].

In this case, the processing is performed on $\mathrm{M}$ implementations of independent Gaussian processes. The average value of these processes in each receiving position is equal to the phased sum of $\mathrm{M}$ echo signals. The initial value of the signal-to-noise is determined by expression (2): 


$$
\mathrm{q}_{\text {out }}^{2}=\mathrm{NM}^{2} \mathrm{q}_{\text {out } 0}^{2}
$$

where $\mathrm{q}_{\text {out } 0}^{2}$ - signal-to-noise ratio at the output of a single-position radar; $\mathrm{N}$ - the number of radars operating in transceiver mode; $\mathrm{M}$-implementations of independent Gaussian processes.

The additional gain in $\mathrm{M}$ times is explained by the fact that at in-phase addition of signals on air object noises of the receiver do not take part, and at coherent addition in receiving devices together with signals incoherent noise develops.

The method of processing coherent signals in a multiradar system of the same type of two-coordinate survey radars with mechanical rotation is proposed in the form shown in Figure 4.
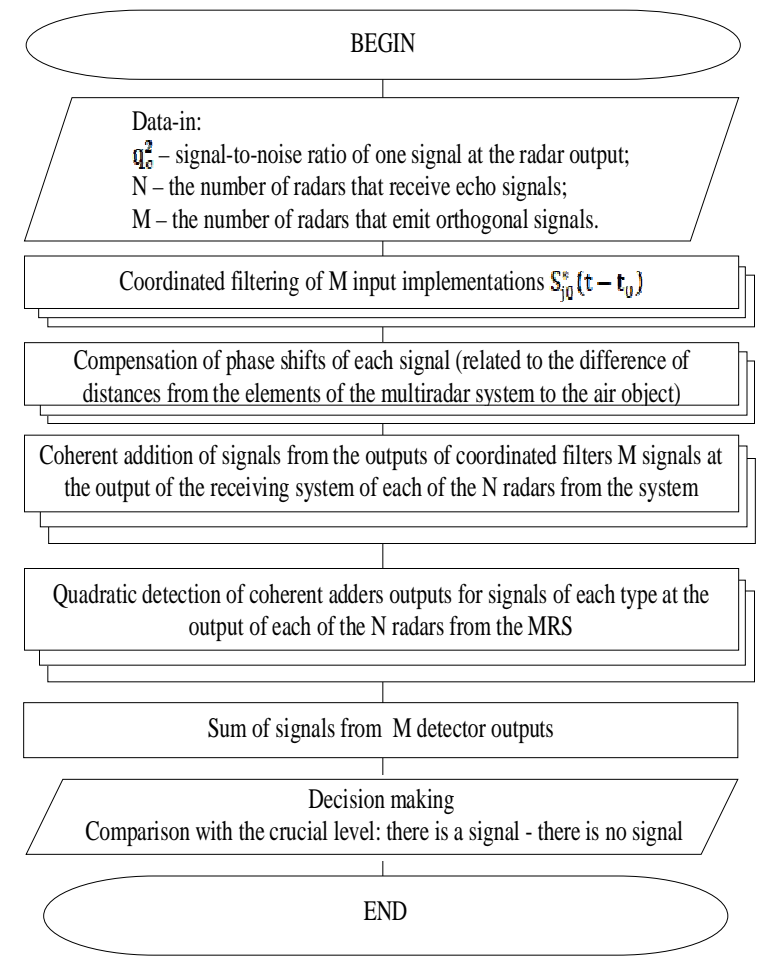

Figure 4. The method of processing coherent signals in a multiradar system
In the case of coherent signal summation and linear detection, the original statistics has a Rayleigh distribution, and in the case of quadratic detection, it has an exponential probability distribution.

If the radar system is able to communicate with the same signals in such a rank, so that they are not in phase with the software, then there will be only one reflected signal at the inputs of the correct positions. An ineffective value of the amplitude of the reflected -signal will, in all cases, provide the sum of the effective values of the reflected -signals, approved by all the transmission positions.

To construct detection curves in both cases, it is convenient to use a known expression for the probability of correct detection and false alarm (expression (3)):

$$
\mathrm{P}_{\mathrm{D}}=\mathrm{P}_{\mathrm{F}}^{1 /\left(1+\overline{\mathrm{q}_{\text {out }}^{2}}\right)} \text {. }
$$

where $\mathrm{P}_{\mathrm{D}}-$ probability of correct detection; $\mathrm{P}_{\mathrm{F}}-$ probability of false alarm; $\mathrm{q}_{\text {out }}^{2}$ - signal-to-noise ratio at the input of a threshold device, which is determined depending on the features of the construction of a spatially coherent multiradar system.

Figure 5 shows the detection curves for a small-base spatially coherent multiradar system. Figure 5 shows the case when all the same type of radar small-base spatial-coherent multiradar system uses the same signals so that their in-phase summation on the air object and at the input of the receiving positions we get only one echo signal. Calculations are given for the operation of one autonomous radar and for the use of a multiradar system with several radars for the probability of false alarm $\mathrm{P}_{\mathrm{F}}=10^{-6}$.

From the analysis of the detection characteristics shown in Figure 5 shows that the transition from a stand-alone radar (curve 1) to a combination of two or three radars (curves 2, 3) leads to a significant shift in the detection characteristics to the left. Increasing the number of coherently combined radars by more than three (curves 4,5 ) does not lead to a significant shift in the detection characteristics to the left compared to the detection characteristics when combining three radars (curve 3 ).

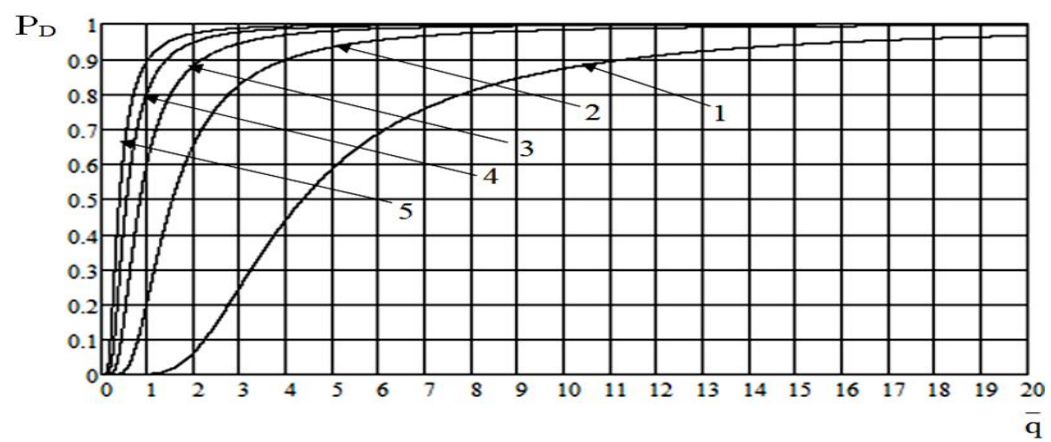

Figure 5. Characteristics of detection of multiradar system: 1 - for autonomous radar;

2 - when using 2 radars in a multiradar system; 3 - when using 3 radars in a multiradar system; 4 - when using 4 radars in a multiradar system; 5 - when using 5 radars in a multiradar system 
Hennadii Khudov et al., International Journal of Emerging Trends in Engineering Research, 8(10), October 2020, 7344 - 7352

In Figure 6 shows the dependence of the win $\mathrm{K}(\mathrm{m})$ in the desired signal-to-noise ratio in a system with $\mathrm{m}$ radar relative to a stand-alone radar to ensure quality indicators of air object detection $\left(\mathrm{P}_{\mathrm{D}}=0,5, \mathrm{P}_{\mathrm{F}}=10^{-6}\right)$ for coherent combining radars.

From the analysis of the dependence of the gain on the signal-to-noise ratio, shown in Fig. 6, it can be concluded that for the case when all similar radars of a small base of a spatially coherent multiradar system use the same type of orthogonal signals, the gain is about $10 \mathrm{~dB}$ when two radars are combined and about $5 \mathrm{~dB}$ with the addition of a third radar, and an increase in gain of only $2.5 \mathrm{~dB}$ with the addition of a fourth radar and additional radars also provide an increase in gain, but the rate of this growth is much lower, which reduces practical significance and economic feasibility. So, summarizing the above, we can conclude that the highest efficiency in terms of signal-to-noise ratio when combining the same spatially distributed radar into a multiradar system is observed when switching from one autonomous radar to a multiradar system with two or three radars.

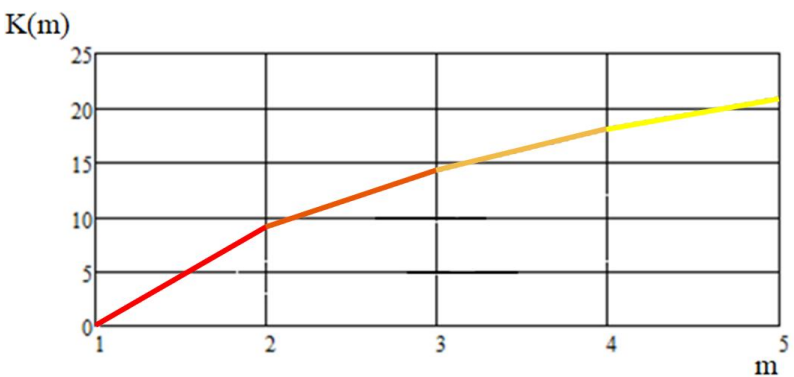

Figure 6. The dependence of winnings in relation signal / noise in a multiradar system in the case when all radars use orthogonal coherent signals

A further increase in the number of radars in each of the two cases is accompanied by a decrease in efficiency due to the addition of each subsequent radar, and it is practically impractical to use in a multiradar system more than four radars with a maximum possible gain of close to $2 \mathrm{~dB}$ with the addition of the last radar from one radar to a multiradar system with two radars.

The addition of second radar for processing coherent and incoherent signals showed the greatest efficiency in terms of signal-to-noise ratio, and in all cases it was shown that the rational number of radars in a multiradar system is no more than four.

Therefore, according to the criterion of efficiency-cost, the most effective is the creation of a spatially coherent multiradar system by combining two to four identical radars.

Thus, in order to improve the quality of detection of an unobtrusive airborne object, it is advisable to create a spatially coherent multiradar system by combining four surveillance radars. Then the expected gain in signal-to-noise ratio can reach $18 \mathrm{~dB}$ if coherent orthogonal signals are used in a small-base system. The use of more than four radars is impractical, since it does not lead to a significant increase in the gain.

\section{CONCLUSION}

Thus, it can be argued that in a multiradar system, you can get the maximum benefit level in terms of signal-to-noise ratio when adding second radar to the system, and the rational number of elements in a multiradar system will be no more than four modules. This is the result of evaluating the system according to the quality-cost criterion. Moreover, this conclusion does not depend on whether the created system is a spatially coherent multiradar system or there will be a case of processing incoherent signals.

Thus, when forming a small-base multiradar system from existing radars to improve the quality of detecting small-sized air objects, it is advisable to create a spatially separated small-base synchronous multi-user system, combining from two to four surveillance radars. If more than four radars are included in the system, then the quality will certainly increase, but this is impractical, because there is no significant increase in the gain. For example, the expected gain in the threshold signal-to-noise ratio when using the proposed signal processing methods in a coherent multiradar system of 4 elements can reach $18 \mathrm{~dB}$, and the use of the fifth radar will add about $3 \mathrm{~dB}$ of gain increase.

The direction of further research is to consider reliable methods for forming a coherent system in the spatial and temporal domains when using spatially separated two-coordinate radars as elements of a synchronous small-sized multiradar system with compatible signal processing

\section{REFERENCES}

1. Armenia Azerbaijan: Reports of fresh shelling dent ceasefire hopes URL: https://www.bbc.com/news/ world-europe-54488386 (accessed 14 October 2020).

2. Civil War in Syria URL: https://www.cfr.org/globalconflict-tracker/conflict/civil-war-syria (accessed 12 October 2020).

3. H. Khudov V. Lishchenko, A. Irkha, and O. Serdjuk, The method of the high accuracy finding $2 \mathrm{D}$ coordinates in MIMO-radar based on existing surveillance radars, 2019 International Conference on Information and Telecommunication Technologies and Radio Electronics, UkrMiCo 2019, Odessa, Ukraine, 2019, pp. 1-4, doi: 10.1109/UkrMiCo47782.2019. 9165319.

4. M. Iasechko, M. Kolmykov, V. Larin, S. Bazilo, H. Lyashenko, P. Kravchenko, N. Polianova, and I. Sharapa Criteria for performing breakthroughs in the holes of radio electronic means under the influence of electromagnetic radiation, ARPN Journal of Engineering and Applied Sciences, Vol. 15. № 12, 2020, pp. 1380-1384. 
5. M. Iasechko, N. Sachaniuk-Kavets'ka, V. Kostrytsia, V. Nikitchenko, and S. Iasechko The results of simulation of the process of occurrence of damages to the semiconductor elements under the influence of the multi-frequency signals of short duration, Journal of Critical Reviews, Vol. 7. № 12, 2020, pp. 109-112. DOI: https://doi.org/10.31838/icr.07.13.18.

6. P. Shchypanskyi, V. Savchenko, O. Martyniuk, and I. Kostiuk, Air Defense Planning from an Impact of a Group of Unmanned Aerial Vehicles based on Multi-Agent Modeling, International Journal of Emerging Trends in Engineering Research, Vol. 8., № 4, 2020, pp. 7-12. DOI: https://doi.org/10.30534/ijeter/2020/59842020.

7. H. Khudov, S. Yarosh, V. Savran, A. Zvonko, A. Shcherba, P. Arkushenko The Technique of Research on the Development of Radar Methods of Small Air Objects Detection, International Journal of Emerging Trends in Engineering Research, Vol. 8. № 7, 2020 , pp. 3708-3715.

DOI: https://doi.org/10.30534/ijeter/2020/132872020.

8. H. Khudov, A. Lykianchykov, D. Okipniak, O.Baranik, O. Ovcharenko, and N. Shamrai The Small Air Objects Detection Method on the Basis of Combination of Single-position and Different Receipt of Signals, International Journal of Emerging Trends in Engineering Research, № 8(8), 2020, pp. 4463-4471. DOI: https://doi.org/10.30534/ijeter/2020/68882020.

9. H. Khudov, I. Khizhnyak, F. Zots, G. Misiyuk, and O. Serdiuk. The Bayes Rule of Decision Making in Joint Optimization of Search and Detection of Objects in Technical Systems, IJETER, № 8(1), 2020, pp. 7-12. DOI: https://doi.org/10.30534/ijeter/2020/02812020.

10. O. Barabash, N. Dakhno, H. Shevchenko, and T. Majsak Dynamic Models of Decision Support Systems for Controlling UAV by Two-Step Variational-Gradient Method, Proceedings of 2017 IEEE 4th International Conference "Actual Problems of Unmanned Aerial Vehicles Developments (APUAVD)”, October 17-19, 2017, Kyiv, Ukraine. pp. 108-111. DOI:https://doi.org/10.1109/APUAVD.2017.8308787

11. H. Khudov, A. Fedorov, D. Holovniak, and G. Misiyuk, Method of Radar Adjustment with Automatic Dependent Surveillance Technology Use, in Intern. Scient.-Pract. Conf. Problems of Infocommunications. Science and Technology (PIC S\&T), 2019, pp. 402-406. DOI:https://doi.org/10.1109/PICST47496.2019.9061245

12. V. Savchenko, H. Haidur, S. Gakhov, S. Lehominova, T. Muzshanova, and I. Novikova Model of Control in a UAV Group for Hidden Transmitters Detection on the Basis of Local Self-Organization, International Journal of Advanced Trends in Computer Science and Engineering, Vol. 9. № 4, 2020, pp. 6167-6174. DOI: https://doi.org/10.30534/ijatcse/2020/291942020.

13. V. Lishchenko, H. Khudov, V. Tiutiunnyk, V._Kuprii, F._Zots, and G._Misiyuk. The Method of Increasing the
Detection Range of Unmanned Aerial Vehicles In Multiradar Systems Based on Surveillance Radars, in 2019 IEEE 39th International Conference on Electronics and Nanotechnology (ELNANO), 2019. P. 559-562. DOI: https://doi.org/10.1109/ELNANO.2019.8783263.

14. H. Khudov, V. Savran, O. Huk, R. Nanivskyi, I. Khizhnyak, and Y. Solomonenko The Information Technology for Building a Test Sequence to Control the Technical Condition of Digital Devices, International Journal of Advanced Trends in Computer Science and Engineering, Vol. 9. № 4, 2020, pp. 5987-5993.

DOI: https://doi.org/10.30534/ijatcse/2020/265942020.

15. H. Khudov, I. Khizhnyak, I. Yuzova, O. Baranik, G. Semiv, S. Bondarenko, and O. Tytarenko. The Optimization Technique for Joint Discrete Search and Detection of Observation Objects, International Journal of Emerging Trends in Engineering Research, № 8(2), 2020, pp. 533-538. DOI: https://doi.org/10.30534/ijeter/2020/42822020.

16. V. Lishchenko, H. Khudov, B. Lisogorsky, O. Baranik, D. Holovniak, and O. Serdjuk The MIMO System on Based Existing Mechanical Rotation Radars with Wide Surveillance Area, in 2020 IEEE 40th International Conference on Electronics and Nanotechnology (ELNANO), 2020. P. 625-628. DOI: https://doi.org/10.1109/ELNANO.50318.2020.90887463

17. H. Khudov, I. Khizhnyak, V. Koval, V. Maliuha, A. Zvonko, V. Yunda, V. Nagachevskyi, and V. Berezanskyi The Efficiency Estimation Method of Joint Search and Detection of Objects for Surveillance Technical Systems, International Journal of Emerging Trends in Engineering Research, Vol. 8. № 3, 2020, pp. 813-819.

18. G. V. Khudov, Features of optimization of two-alternative decisions by joint search and detection of objects. Problemy Upravleniya I Informatiki (Avtomatika), 2003, № 5, pp. 51-59.

19. V. Lishchenko, V. Chaliy, H. Khudov, and A. Zvonko. Proposals for Improving of Air Surveillance Informativity in MIMO Radar Systems Based on Two-Dimensional Radars, in Intern. Scient.-Pract. Conf. Problems of Infocommunications. Science and Technology (PICS\&T), 2018, pp. 153-156. DOI: https://doi.org/10.1109/infocommst.2018.8632052.

20. V. Tarshyn, A. Tantsiura, Y. Kozhushko, V. Vasylyshyn, V. Mosharenkov, and Y. Tarshyna The Objects Detection Increasing Probability Method on Integrated Images of the Sight Surface in Difficult Observation Conditions, International Journal of Emerging Trends in Engineering Research, № 8(8), 2020, pp. 4659-4665.

DOI: https://doi.org/10.30534/ijeter/2020/99882020.

21. H. Khudov, A. Zvonko, S. Kovalevskyi, V. Lishchenko, and F. Zots. Method for the detection of smallsized air objects by observational radars, Eastern-European 
Hennadii Khudov et al., International Journal of Emerging Trends in Engineering Research, 8(10), October 2020, 7344 - 7352

Journal of Enterprise Technologies, № 2/9 (92), 2018, pp. 61-68.

DOI:

https://doi.org/10.15587/1729-4061.2018.126509.

22. I. Ruban, H. Khudov, V. Lishchenko, A. Zvonko, S. Glukhov, I. Khizhnyak, V. Maliuha, Y. Polonskyi, R. Kushpeta, The Calculating Effectiveness Increasing of Detecting Air Objects by Combining Surveillance Radars into The Coherent System, International Journal of Emerging Trends in Engineering Research, Vol. 8., № 4, 2020, pp. 1295-1301. DOI: https://doi.org/10.30534/ijeter/2020/58842020.

23. H. Khudov, A. Zvonko, I. Khizhnyak, V. Shulezko, V. Khlopiachyi, V. Chepurnyi, and I. Yuzova. The Synthesis of the Optimal Decision Rule for Detecting an Object in a Joint Search and Detection of Objects by the Criterion of Maximum Likelihood, International Journal of Emerging Trends in Engineering Research, № 8(2), 2020, pp. 520-524. DOI: https://doi.org/10.30534/ijeter/2020/40822020.

24. M. Iasechko, V. Larin, D. Maksiuta, S. Bazilo, and I. Sharapa The method of determing the probability of affection of the semiconductor elements under the influence of the multifrequency space-time signals, Journal of Critical Reviews, Vol. 7. № 9, 2020, pp. 569-571.

DOI:

https://doi.org/10.31838/icr.07.09.113.

25. H. Khudov， S. Glukhov， O. Maistrenko, A. Fedorov, A. Andriienko, O. Koplik, The Method of ADS-B Receiver Systems Synchronization Using MLAT Technologies in the Course of Radar Control of Air Environment, International Journal of Emerging Trends in Engineering Research, Vol. 8. № 5, 2020, pp. 1946-1951. DOI: https://doi.org/10.30534/ijeter/2020/78852020.

26. V. Lishchenko, T. Kalimulin, I. Khizhnyak, and H. Khudov, The method of the organization coordinated work for air surveillance in MIMO radar, Paper presented at the 2018 International Conference on Information and Telecommunication Technologies and Radio Electronics, UkrMiCo, 2018 - Proceeding.

DOI:

https://doi.org/doi:10.1109/ UkrMiCo43733.2018.9047560.

27. H. Khudov, A. Fedorov, D. Holovniak, and G. Misiyuk. Improving the Efficiency of Radar Control of Airspace with the Multilateration System Use, in Intern. Scient.-Pract. Conf. Problems of Infocommunications. Science and Technology (PIC S\&T), 2018, pp. 680-684. DOI: https://doi.org/10.1109/infocommst.2018.8632141.

28. H. Khudov， S. Kovalevskyi， A. Irkha， V. Lishchenko, O. Serdiuk and F. Zots, The Proposals for Synchronization Positions of MIMO Radar System on the Basis of Surveillance Radars, in Intern. Scient.-Pract. Conf. Problems of Infocommunications. Science and Technology (PIC S\&T), 2019, pp. 547-551. DOI:

https://doi.org/10.1109/PICST47496.2019.9061284.
29. H. Khudov, S. Glukhov, A. Halosa, V. Hudyma, A. Zvonko, and I. Yuzova, The Energodynamic Method of Diagnostics of Electronic Equipment Digital Devices, International Journal of Emerging Trends in Engineering Research, Vol. 8. № 9, 2020, pp. 5681-5687. DOI: https://doi.org/10.30534/ijatcse/2020/125892020.

30. H. Khudov, B. Lisogorsky, S. Sokolovskyi, A. Ostrovskyi, V. Losa, and I. Khizhnyak, The Method of Increasing Resolution in Network of Radars type as AN/TPQ-49, International Journal of Emerging Trends in Engineering Research, Vol. 8. № 9, 2020, pp. 5726-5732.

DOI: https://doi.org/10.30534/ijatcse/2020/132892020.

31. H. Khudov, V. Lishchenko, B. Lanetskii, V. Lukianchuk, S. Stetsiv, and I. Kravchenko The coherent signals processing method in the multiradar system of the same type two-coordinate surveillance radars with mechanical azimuthal rotation, International Journal of Emerging Trends in Engineering Research, Vol. 8. № 6, 2020, pp. 2624-2630. DOI: https://doi.org/10.30534/ijeter/2020/66862020.

32. I. Ruban, and H. Khudov, Advances in Spatio-Temporal Segmentation of Visual Data, Chapter 2. Swarm Method of Image Segmentation. Series Studies in Computational Intelligence (SCI), Vol. 876. - Publisher Springer, Cham, $2020 . \quad-\quad$ P. 53-99. DOI https://doi.org/10.1007/978-3-030-35480-0.

33. H. Khudov, V. Lishchenko, H. Hyshko, Y. Polonskyi, I. Khizhnyak, B. Riabukha, The MIMO Surveillance Radars System with High Accuracy Finding 2D Coordinates, International Journal of Emerging Trends in Engineering Research, Vol. 8. № 5, 2020, pp. 2026-2030.

DOI: https://doi.org/10.30534/ijeter/2020/91852020.

34. M. Iasechko, N. Sachaniuk-Kavets'ka， V. Kostrytsia, V. Nikitchenko, and S. Iasechko, The results of simulation of the process of occurrence of damages to the semiconductor elements under the influence of the multi-frequency signals of short duration, Journal of Critical Reviews, Vol. 7. № 12, 2020, pp. 109-112. DOI: https://doi.org/10.31838/icr.07.13.18.

35. Drone defence URL: https://www.rheinmetall-defence. com/en/rheinmetall_defence/public_relations/themen_im _fokus/drohnenabwehr/index.php (accessed 10 October 2020).

36. H. Khudov， S. Glukhov， V. Podlipaiev， V. Pavlii, I. Khizhnyak, and I. Yuzova The Multiscale Image Processing Method from On-board Earth Remote Sensing Systems Based on the Artificial Bee Colony Algorithm, International Journal of Advanced Trends in Computer Science and Engineering, Vol. 9. № 3, 2020, pp. 2557-2562.

DOI: https://doi.org/10.30534/ijatcse/2020/11932020.

37. I. Ruban, H. Khudov, O. Makoveichuk, I. Khizhnyak, N. Lukova-Chuiko, G. Pevtsov, Y. Sheviakov, I. Yuzova, Y. Drob, and O. Tytarenko, Method for determining 
elements of urban infrastructure objects based on the results from air monitoring, Eastern-European Journal of Enterprise Technologies, № 4/9 (100), 2019, pp. $52-61$.

DOI: https://doi.org/10.15587/1729-4061.2019.174576.

38. H. Khudov, I. Ruban, O. Makoveichuk, H. Pevtsov, V. Khudov, I. Khizhnyak, S. Fryz, V. Podlipaiev, Y. Polonskyi, and R. Khudov. Development of methods for determining the contours of objects for a complex structured color image based on the ant colony optimization algorithm, Eureka: Physics and Engineering, № 1, 2020, pp. 34-47. DOI: https://doi.org/10.21303/2461-4262.2020.001108.

39. H. Khudov, R. Khudov, I. Khizhnyak, V. Loza, T. Kravets, S. Kibitkin Estimation of the Kullback-Leibler Divergence for Canny Edge Detector of Optoelectronic Images Segmentation, International Journal of Emerging Trends in Engineering Research, Vol. 8. № 7, 2020, pp. 3927-3934. DOI: https://doi.org/10.30534/ijeter/2020/162872020.

40. I. Ruban, H. Khudov, O. Makoveychuk, I. Khizhnyak, V. Khudov, and V. Lishchenko The model and the method for forming a mosaic sustainable marker of augmented reality. 2020 IEEE 15 th Inter. Conf. on Advanced Trends in Radioelectronics, Telecommunications and Engineering (TCSET), February 2020. https://doi.org/10.1109/TCSET49122.2020.235463.

41.I. Ruban, H. Khudov, O. Makoveichuk, M. Chomik, V. Khudov, I. Khizhnyak, V. Podlipaiev, Y. Sheviakov, O. Baranik, and A. Irkha. Construction of methods for determining the contours of objects on tonal aerospace images based on the ant algorithms, Eastern-European Journal of Enterprise Technologies, № 5/9 (101), 2019, pp. $25-34$. https://doi.org/10.15587/1729-4061.2019.177817.

42. I. Ruban, V. Khudov, H. Khudov, and I. Khizhnyak An Improved Method for Segmentation of a Multiscale Sequence of Optoelectronic Images, in Intern. Scient.-Pract. Conf. Problems of Infocommunications. Science and Technology (PIC S\&T), 2017, pp. 137-140. DOI: https://doi.org/10.1109/INFOCOMMST.2017.8246 367.

43. I. Ruban, O. Makoveichuk, V. Khudov, I. Khizhnyak, H. Khudov, I. Yuzova, and Y. Drob. The Method for Selecting the Urban Infrastructure Objects Contours, in Intern. Scient.-Pract. Conf. Problems of Infocommunications. Science and Technology (PIC S\&T), 2019, pp. 689-693. DOI: https://doi.org/10.1109/infocommst.2018.8632045.

44. H. Khudov, O. Makoveychuk, I. Khizhnyak, I. Yuzova , A. Irkha, and V. Khudov. The Mosaic Sustainable Marker Model for Augmented Reality Systems, International Journal of Advanced Trends in Computer Science and Engineering, Vol. 9. № 1, 2020, pp. 637-642.

DOI: https://doi.org/10.30534/ijatcse/2020/89912020.
45. I. Ruban, H. Khudov, V. Khudov, I. Khizhnyak, and O. Makoveichuk. Segmentation of the images obtained from onboard optoelectronic surveillance systems by the evolutionary method, Eastern-European Journal of Enterprise Technologies, № 5/9 (89), 2017, pp. 49-57. DOI: https://doi.org/10.15587/1729-4061.2017.109904.

46. I. Ruban, V. Khudov, O. Makoveichuk, H. Khudov, and I. Khizhnyak. A Swarm Method for Segmentation of Images Obtained from On-Board Optoelectronic Surveillance Systems, in Intern. Scient.-Pract. Conf. Problems of Infocommunications. Science and Technology (PIC S\&T), 2018, pp. 613-618. DOI: https://doi.org/10.1109/infocommst.2018.8632045.

47. I. Ruban, H. Khudov, O. Makoveichuk, I. Khizhnyak, V. Khudov, V. Podlipaiev, V. Shumeiko, O. Atrasevych, A. Nikitin, and R. Khudov. Segmentation of opticalelectronic images from on-board systems of remote sensing of the Earth by the artificial bee colony method, Eastern-European Journal of Enterprise Technologies, № 2/9 (98), 2019, pp. 37-45. DOI: https://doi.org/10.15587/1729-4061.2019.161860.

48. H. Khudov, I. Ruban, V. Lysytsya, P. Kuzyk, O. Symkanych, and R. Khudov, The Method for Determination of Bone Marrow Cells in Photographic Images, International Journal of Emerging Trends in Engineering Research, Vol.8. № 9, 2020, pp. 5681-5687.

DOI: 